\title{
INFLUENCE OF MICROLEAKAGE, SURFACE ROUGHNESS AND BIOFILM CONTROL ON SECONDARY CARIES FORMATION AROUND COMPOSITE RESIN RESTORATIONS: AN IN SITU EVALUATION
}

\author{
Fábio Garcia LIMA ${ }^{1}$ Ana Regina ROMANO ${ }^{2}$, Marcos Britto CORREA ${ }^{3}$, Flávio Fernando DEMARCO ${ }^{4}$
}

1- DDS, MSc, PhD, Associate Professor, Department of Operative Dentistry, University of Western Santa Catarina, Joaçaba, SC, Brazil.

2- DDS, MSc, PhD, Associate Professor, Department of Cariology, Pediatric and Preventive Dentistry, Dental School, Federal University of Pelotas,

Pelotas, RS, Brazil.

3- DDS, Undergraduate Student, Department of Operative Dentistry, Dental School, Federal University of Pelotas, Pelotas, RS, Brazil.

4- DDS, PhD, Associate Professor, Department of Operative Dentistry, Dental School, Federal University of Pelotas, Pelotas, RS, Brazil.

Corresponding address: Prof. Dr. Flávio Fernando Demarco - Faculdade de Odontologia - Universidade Federal de Pelotas - Rua Gonçalves Chaves, 457, $5^{\circ}$ andar - Centro - 96015568 - Pelotas, RS - Brasil - Phone/Fax: +55-53-3222-6690 - Ext.: 135 - e-mail: flavio.demarco@pq.cnpq.br

Received: March 18, 2008 - Modification: July 10, 2008 - Accepted: August 30, 2008

\begin{abstract}
This

his study was carried out to evaluate in situ the influence of microleakage, surface roughness and biofilm control on caries formation around composite resin restorations. During 28 days, 12 volunteers wore palatal devices containing bovine enamel slabs restored with composite resin. Restorations were made without leakage, when the adhesive system was applied, or with leakage, when adhesive system was omitted. Half of the restorations in each group were finished and the remaining were finished and polished. In one side of the palatal device, biofilm was left to accumulate over the restored slabs, and in the other side dental slabs were brushed, to allow biofilm removal. There was an extraoral application of $20 \%$ sucrose solution (8x/day) over the enamel slabs. The formation of caries lesions (white spots) was evaluated by visual inspection under stereomicroscopy. Additionally, the dental slabs were sectioned and observed under polarized light microscopy. Data were submitted to Kruskal-Wallis test and Spearman's correlation test at 5\% significance level. Polishing and bonding were not significant factors regarding white spot formation ( $\mathrm{p}>0.05$ ). Biofilm control (brushing) was associated with reduction of caries formation close to the restorations $(\mathrm{p}<0.01)$. Polarized light microscopy confirmed the visual inspection findings. These results suggest that while microleakage and surface roughness did not influence caries lesion formation, biofilm control may prevent the enamel demineralization.
\end{abstract}

Key Words: Biofilm. Dental caries. Dental leakage. Dental plaque.

\section{INTRODUCTION}

It has been reported that dentists spend $60 \%$ to $75 \%$ of their working time replacing restorations ${ }^{11}$, which causes high personal and social costs ${ }^{7}$. The replacement of restorations is mainly related to the occurrence of secondary caries $^{15,19}$. Secondary caries might be considered primary lesions around restorations ${ }^{15}$ and they can be also known as "dental caries near to restorations"21. The main locations are areas of biofilm stagnation, such as the cervical margins of restorations ${ }^{16}$. Secondary caries may appear as a wall lesion or a superficial lesion adjacent or next to a restoration ${ }^{8}$.

The inherent polymerization shrinkage of composites can produce gap formation between tooth/restoration ${ }^{5}$. Microleakage has been strongly associated to marginal gap ${ }^{3}$, and in vitro studies have associated the presence of secondary caries with microleakage ${ }^{6}$. However, clinical findings have not supported this association ${ }^{15}$.

A smooth surface is very important for esthetics and longevity of restorations and this surface can be obtained with proper finishing and polishing procedures. Dental restorative materials with surface characteristics different from the tooth might affect pellicle formation and the ability of bacteria to colonize the oral cavity ${ }^{4,14}$. Rougher restorations could favor dental biofilm retention, producing superficial staining, gingival inflammation and dental caries $^{20}$.

Biofilm accumulation on dental structure can lead to caries occurrence and the mechanical action of tooth brushing produces biofilm disorganization, which can prevent or arrest caries development ${ }^{10}$.

This study aimed to evaluate in situ the effect of microleakage, surface roughness and biofilm control on enamel caries around composite resin restorations. 


\section{MATERIAL AND METHODS}

\section{Ethical Aspects}

The research protocol had the approval of the local Research Ethics Committee. Twelve undergraduate dental students were selected as volunteers (aged 20 to 25 years; 7 males and 5 females). Volunteers were informed about the objectives of the study and they signed a written consent form to participate.

\section{Preparation of Enamel Slabs}

Enamel slabs $(10 \times 6 \times 3 \mathrm{~mm})$ were prepared from the middle third of recently extracted bovine incisors, using a diamond saw under water cooling. In each one of the 48 enamel blocks, two box-shaped standardized cavities (2.5 x $1.0 \times 1.5 \mathrm{~mm}$ ) were prepared at a $2-\mathrm{mm}$ distance from each other, using carbide burs at high-speed rotation and under water/air spray cooling. Specimen distribution in the different groups is demonstrated in Table 1. The slabs were sterilized in humid heat at $120^{\circ} \mathrm{C}$ for $15 \mathrm{~min}$ and kept moist throughout the study in sterile saline solution.

\section{Restorative Procedures}

A pilot study developed in our laboratory determined that composite resin restorations without adhesive system application presented the highest leakage values, while none or minimal leakage was observed in those restorations where adhesive system was applied. Based on these findings, for the in situ study, half of the composite resin restorations (A) were performed with Single Bond adhesive system (3M/ ESPE, Sumaré, SP, Brazil) and the others were restored without adhesive (NA). All cavities were incrementally filled with composite resin (Z250, 3M/ESPE). A XL 2500 photocuring unit (3M/ESPE) was used for photo activation of the materials.

Each group was randomly divided in two subgroups according to surface treatments: restorations only finished (F) with diamond burs (KG Sorensen, Alphaville, SP, Brazil), and restorations finished (diamond burs) and polished (FP), using Sof-Lex disks (3M/ESPE).

\section{Preparation of the Palatal Devices}

A custom-made acrylic resin intraoral palatal device containing two cavities on each side, where the slabs were adapted, was made for each volunteer. Plastic meshes were fixed in one side leaving a 1-mm space for accumulation of dental biofilm on the slabs ${ }^{9}$. The other side remained uncovered, allowing brushing of the enamel slabs.

\section{Clinical Phase}

Throughout the experiment, the volunteers were oriented to brush their teeth with a specially developed non-fluoride dentifrice. Cariogenic challenge to the restored specimens was caused by dripping a $20 \%$ sucrose solution onto all slabs, 8 times/day. These procedures were performed for 28 days. The volunteers were instructed to wear the devices during all the day and they should only remove them for sucrose application and food or beverage ingestion. During meal times, the devices were kept moist in plastic receptacles. The volunteers brushed the uncovered slabs with the nonfluoride dentifrice three times a day. The only contact with fluoride was the intake of public supplied water, containing 0.6 to $1.0 \mathrm{ppmF}$. The compliance of the volunteers was measured by a written personal daily report.

\section{Enamel Demineralization Analyses}

After the experimental clinical phase the enamel slabs were removed from the intraoral devices. The analysis of demineralization around composite resin restorations was made by an experienced blinded examiner under stereomicroscopy (x40) after 15-s air-drying. Caries lesion was classified as follow: 0: sound enamel and 1: white spot lesion.

Two specimens of each group were randomly selected and were submitted to evaluation under polarized light microscopy. These specimens were sectioned with low-speed diamond saw under water cooling and were serially polished with 600-, 1000- and 1200-grit sandpapers), obtaining a final thickness of approximately $80 \mu \mathrm{m}$ for each slice. The slices were stored in distilled water for $24 \mathrm{~h}$ and were then qualitatively analyzed by another experienced blinded examiner.

TABLE 1- Distribution of the enamel blocks according to adhesive system, surface treatment and biofilm control

\begin{tabular}{lll}
\hline Adhesive System & Surface treatment & Biofilm control \\
\hline With (A) $(n=48)$ & Finishing $(F)(n=24)$ & $\begin{array}{l}\text { brushing (B) }(n=12) \\
\text { without (NB) }(n=12)\end{array}$ \\
& Polishing (FP) $(n=24)$ & brushing (B) $(n=12)$ \\
& & without (NB) $(n=12)$ \\
Without (NA) $(n=48)$ & Finishing (F) $(n=24)$ & brushing (B) $(n=12)$ \\
& & without (NB) $(n=12)$ \\
& Polishing (FP) $(n=24)$ & brushing (B) $(n=12)$ \\
& without (NB) $(n=12)$
\end{tabular}




\section{Statistical Analysis}

Data from visual inspection were submitted to statistical analysis by non-parametric Kruskal-Wallis test. The correlation between the tested variables and caries formation next to the composite resin restorations was tested with Spearman's correlation. The significance level was set at $95 \%$.

\section{RESULTS}

The presence or absence of caries next to restorations in each group is shown in Table 2. No significant effect of bonding condition (A $x$ NA) was found regarding enamel mineral loss ( $p>0.05$ ). Also, finished restoration had similar occurrence of white spot lesions when compared to polished restorations $(p>0.05)$. The only significant variable was biofilm control. Enamel slabs subjected to biofilm accumulation produced a significantly larger number of white spot lesions than those where brushing was performed $(\mathrm{p}<0.01)$.

When the association between variables (microleakage, surface roughness and biofilm control) and white lesions formation was tested (Table 3), biofilm control was the only variable that significantly influenced the presence of caries next to a restoration $(\mathrm{p}<0.001)$.

When the specimens were observed under polarized light microscopy there was concordance with visual inspection. In this observation, birefringent zones (Figure 1) were observed indicating caries formation. Cavited lesions were observed around composite resin restoration (Figure 1) and also superficial lesions were detected without association with the restorations (Figure 2).

TABLE 2- Scores of caries formation around composite restorations for each group in the different conditions evaluated

\begin{tabular}{lrr}
\hline Groups & Score $\mathbf{0}$ & Score $\mathbf{1}$ \\
\hline AFNB & 2 & 10 \\
AFB & 10 & 2 \\
APNB & 2 & 10 \\
APB & 8 & 4 \\
NAFNB & 3 & 9 \\
NAFB & 12 & 0 \\
NAPNB & 0 & 10 \\
NAPB & 10 & 2 \\
\hline
\end{tabular}

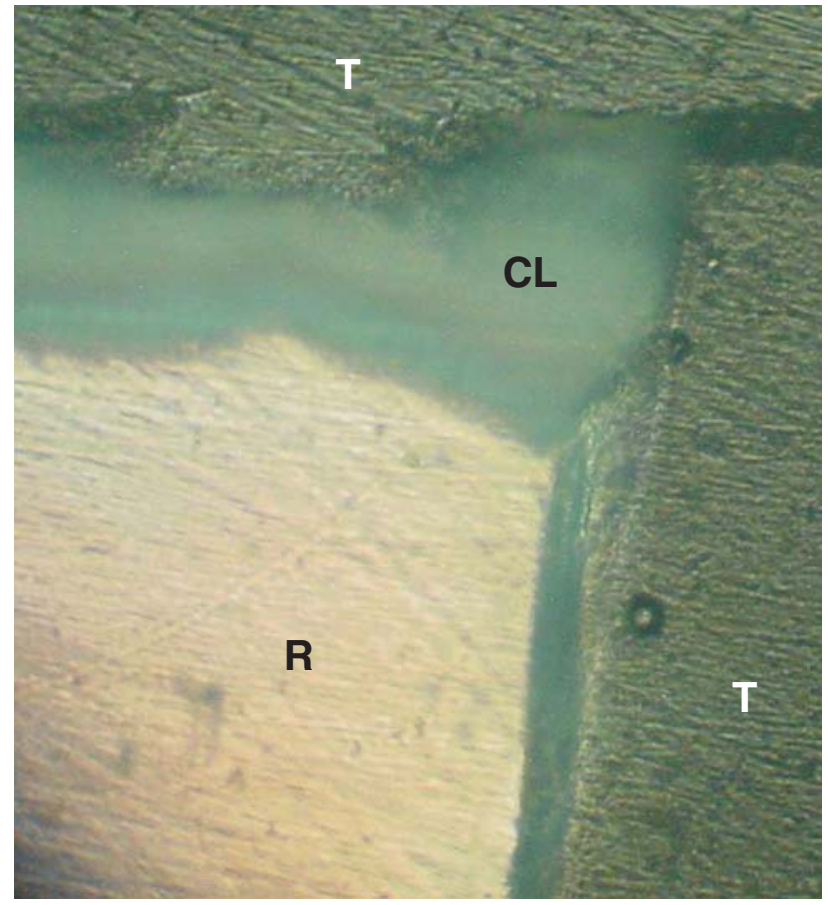

FIGURE 1- Polarized light microscopy indicating birefringent zones around restoration. Restoration (R), Caries lesion $(\mathrm{CL})$, Tooth (T)

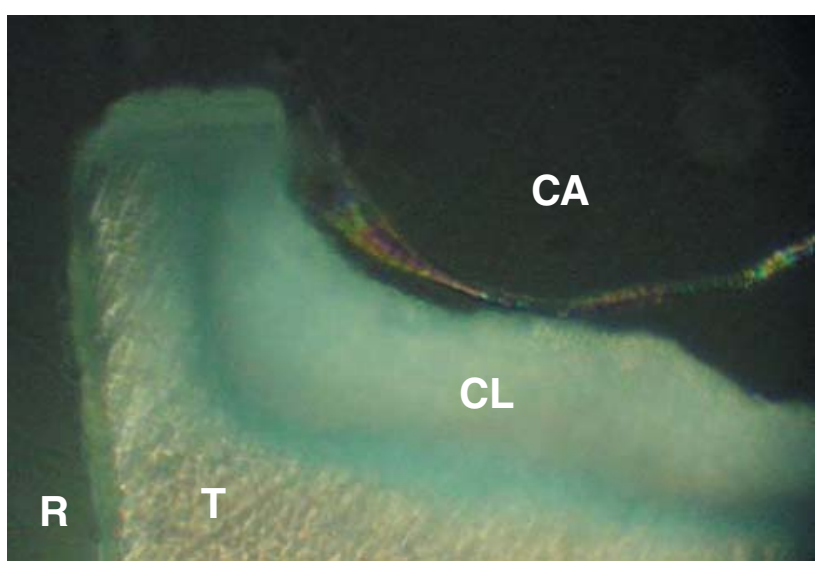

FIGURE 2- Polarized light microscopy showing caries lesion (CL) with cavitation (CA) without association with the restoration $(\mathrm{R})$. Tooth $(\mathrm{T})$

TABLE 3- Correlation between the variables studied and white spot lesion formation

\begin{tabular}{lcc}
\hline Variables crossing & Spearman's correlation coefficient & p value \\
\hline White spot lesion X microleakage & -0.104 & 0.312 \\
White spot lesion X surface roughness & -0.021 & 0.840 \\
White spot lesion X biofilm control & 0.646 & 0.001 \\
\hline
\end{tabular}




\section{DISCUSSION}

This in situ study was designed to evaluate the effects of microleakage, surface roughness and biofilm control on the occurrence of caries next to composite resin restoration. Bovine teeth were used as source of enamel slabs. More preventive approach in dentistry and ethical concerns have limited the availability of human teeth for research protocols. Bovine teeth have been proven to be a suitable substitute of human teeth for demineralization studies ${ }^{1}$.

The findings demonstrated that the presence of microleakage at the adhesive interface did not affect significantly the enamel demineralization, reinforcing the lack of association between microleakage and caries adjacent to restoration ${ }^{4,11,15,19}$. Microleakage is still considered an etiologic factor for secondary caries ${ }^{6}$, but most of these studies were performed in vitro ${ }^{7}$. In this study, we only evaluated the superficial lesions formed around restorations. There was no evaluation concerning the wall lesions formed at the tooth/restoration margin, which is a limitation of the study.

Bacterial adhesion on the surface of composite resins has been considered an important parameter in the etiology of caries formation around restorations ${ }^{17}$. However, a highly polished surface of composite is difficult to achieve because of factors such as different amounts of filler particles, the size of particles, and the different hardness between filler particles and organic matrix of the composite ${ }^{20}$. The objective of placing an esthetic restoration is to reproduce as close as possible the natural appearance of the tooth and it is important to obtain the smoothest surface that will minimize dental biofilm accumulation and stain retention ${ }^{18}$. In the present study, no significant difference was observed between finished or polished restorations in relation to the presence of white spot lesions. These findings corroborate the results obtained in other studies, where no association was detected between the surface roughness values and the bacterial adhesion ${ }^{17,22}$.

It is important to emphasize that extremely severe conditions were tested in this study: total accumulation of dental biofilm (under the plastic mesh), without any mechanical disturbance; and biofilm control (brushing 3 times/day). Biofilm control showed a statistically significant correlation with white spot lesion formation.

The disorganization of the cariogenic biofilm plays an important role in the control of the caries disease ${ }^{19}$. Holmen, et al. ${ }^{10}$ (1987) observed that the self-control of biofilm was efficient in the prevention and in the arrestment of the noncavited caries lesions. The role of operative dentistry in caries management is to restore the integrity of the tooth surface allowing patients to improve cleaning ${ }^{12}$. In restored teeth, the so-called secondary caries is not a new lesion, but it is a continuation of the previous caries activity that was not arrested ${ }^{12,16,19}$. Therefore, the management of the new lesion should follow the same approach used to treat the primary lesion, which relies on the reduction of sucrose intake, rational use of fluoride and cariogenic biofilm control $^{9}$.
In this in situ study, the volunteers had restrained the contact to fluoride to that present in the public supplied water. Non-fluoride toothpaste was provided for brushing of the volunteer's teeth and enamel slabs. However, the characteristics of the volunteers' saliva (buffering ability or salivary flow) were not evaluated.

It should be pointed out that visual and tactile inspection of caries lesions has limited sensibility because subclinical demineralization undetectable for the naked human eye could occur ${ }^{13}$. In this study only superficial lesions were possible to evaluate by visual inspection. The occurrence of wall lesions was not investigated. Nevertheless, the examination under polarized light has confirmed the presence of caries lesions next to restorations observed clinically in this study.

Currently, significant economic and intellectual efforts have been directed to produce leakage-free restorations and materials that release fluoride aiming to prevent caries formation around restoration, which ultimately have been considered the main reason for restoration replacement. However, the educational approach to promote oral health should be emphasized as the fundamental tool for caries prevention.

\section{CONCLUSIONS}

Within the limitations of this in situ study, it may be concluded that microleakage and surface roughness have not influenced the formation of white spot lesions around composite resin restorations, while biofilm control has significantly influenced the superficial demineralization of the bovine enamel.

\section{REFERENCES}

1-Attin T, Weiss K, Becker K, Buchalla W, Wiegand A. Impact of modified acidic soft drinks on enamel erosion. Oral Dis. 2005;11(1):7-12

2- Benelli EM, Serra MC, Rodrigues ALJr, Cury JA. In situ anticariogenic potential of glass ionomer cement. Caries Res. 1993;27(4):280-4.

3- Boeckh C, Schumacher E, Podbielski A, Haller B: Antibacterial activity of restorative dental biomaterials in vitro. Caries Res. 2002;36(2):101-7.

4- Cenci MS, Tenuta LM, Pereira-Censi T, Del Bel Cury AA, Ten Cate JM, Cury JA. Effect of microleakage and fluoride on enamel-dentine demineralization aroud restorations. Caries Res. 2008;42(5):369-79.

5- Eick JD, Gwinnett AJ, Pashley DH, Robinson SJ. Current concepts on adhesion to dentin. Crit Rev Oral Biol Med. 1997;8(3) 306-35.

6- Fontana M, González-Cabezas C. Secondary caries and restoration replacement: an unresolved problem. Compend Contin Educ Dent. 2000;21(1):15-26.

7- Gilmour AS, Edmunds DH. The polarized light microscopic appearance of caries-like lesion adjacent to restored cavities in the crowns and roots of extracted human teeth. J Oral Rehabil. 1998;25(12):929-39.

8- Hals E, Nernaes A: Histopathology of in vitro caries developing around silver amalgam fillings. Caries Res. 1971;5:58-77. 
9- Hara AT, Magalhães CS, Serra MC, Rodrigues AL Jr. Cariostatic effect of fluoride-containing restorative systems associated with dentifrices on root dentin. J Dent. 2002;30(5-6):205-12.

10- Holmen L, Thylstrup A, Artun J. Clinical and histological features observed during arrestment of active enamel carious lesions in vivo. Caries Res. 1987;21(6):546-54.

11- Kidd EAM, Joyston-Bechal S, Beighton D. Diagnosis of secondary caries: a laboratory study. Br Dent J. 1994;176(4):135-9.

12- Kidd EAM. Diagnosis of secondary caries. J Dent Educ 2001;65(10):997-1000

13- Kotsanos N. An intraoral study of caries induced on enamel in contact with fluoride-releasing restorative materials. Caries Res. 2001;35(3):2004.

14- Marsh Pd, Nyvad B. The oral microflora and biofilm on teeth; in Fejerskov O, Kidd EAM. Dental Caries: the disease and Its clinical management, Oxford; Blackwell Munksgaard; 2003. p 29-48.

15- Mjör IA. Clinical diagnosis of recurrent caries. J Am Dent Assoc. $2005 ; 136: 1426-33$

16- Mjör IA, Toffenetti F. Secondary caries: a literature review with case reports. Quintessence Int. 2000;31(3):165-79.

17- Montanaro L, Campoccia D, Rizzi S, Donati ME, Breschi L, Prati C, et al. Evaluation of bacterial adhesion of Streptococcus mutans on dental restorative materials. Biomaterials. 2004;25(18):4457-63.

18- Neme AL, Frazier KB, Roeder LB, Debner TL. Effect of prophylactic polishing protocols on the surface roughness of esthetic restorative materials. Oper Dent. 2002;27(1):50-8.

19- Özer L, Thylstrup A. What is known about caries in relation to restorations as a reason for replacement? A review. Adv Dent Res. 1995;9(1):394-402

20- Reis AF, Giannini M, Lovadino JR, Santos Dias CTdos. The effect of six polishing systems on the surface roughness of two packable resinbased composites. Am J Dent. 2002;15(3):193-7.

21- Thomas RZ, Ruben JL, ten Bosch JJ, Fidler V, Huysmans MC. Approximal secondary caries lesion progression, a 20-week in situ study. Caries Res. 2007:41(5):399-405.

22- Yamamoto K, Ohashi S, Taki E, Hirata K. Adherence of oral streptococci to composite resin of varying surface roughness. Dent Mater J. 1996;15(1):201-4. 